\title{
Efficacy and Tolerability of Second-Line Metronidazole Triple Therapy Using Vonoprazan for Helicobacter pylori Eradication in Japan-Comparative Study: Vonoprazan vs. Proton Pump Inhibitors
}

\author{
Masahiko Ohtaka1,2, Mika Miura1,2, Mitsuhiko Hanawa1,2, Yuichi Hirose1, Atsuko Kitahashi1, \\ Naoki Imamura1, Ikko Watanabe', Kazuhiko Takaso', Naoki Shimura1, Yoshioki Yoda', \\ Ichiro Takayama ${ }^{3}$, Mitsuharu Fukasawa², Nobuyuki Enomoto ${ }^{2}$ \\ ${ }^{1}$ Yamanashi Koseiren Health Care Center, Yamanashi, Japan \\ ${ }^{2}$ First Department of Internal Medicine, Graduate School of Medical and Engineering Science, University of Yamanashi, \\ Yamanashi, Japan \\ ${ }^{3}$ Health Care Center, University of Yamanashi, Yamanashi, Japan \\ Email: *mohtaka@yamanashi.ac.jp
}

How to cite this paper: Ohtaka, M., Miura, M., Hanawa, M., Hirose, Y., Kitahashi, A., Imamura, N., Watanabe, I., Takaso, K., Shimura, N., Yoda, Y., Takayama, I., Fukasawa, M. and Enomoto, N. (2018) Efficacy and Tolerability of Second-Line Metronidazole Triple Therapy Using Vonoprazan for Helicobacter pylori Eradication in Japan-Comparative Study: Vonoprazan vs. Proton Pump Inhibitors. Open Journal of Gastroenterology, 8, 27-38.

https://doi.org/10.4236/ojgas.2018.81003

Received: December 5, 2017

Accepted: January 28, 2018

Published: January 31, 2018

Copyright $\odot 2018$ by authors and Scientific Research Publishing Inc. This work is licensed under the Creative Commons Attribution International License (CC BY 4.0).

http://creativecommons.org/licenses/by/4.0/

c) (i) Open Access

\begin{abstract}
Aim: To investigate the efficacy and tolerability of second-line metronidazole triple therapy with vonoprazan (VPZ) for Helicobacter pylori (H. pylori). Methods: We retrospectively reviewed medical records of patients who experienced clarithromycin triple therapy failure and were treated with secondline (20 mg VPZ ( $\mathrm{n}=274) / 30 \mathrm{mg}$ lansoprazole $(\mathrm{n}=323)$ or $10 \mathrm{mg}$ rabeprazole ( $\mathrm{n}=141$ ) twice daily, $750 \mathrm{mg}$ amoxicillin twice daily, $250 \mathrm{mg}$ metronidazole twice daily for 7 days) eradication therapies. Successful eradication rates were compared between two groups: those receiving VPZ and those receiving a proton pump inhibitor (PPI). Adverse events were also investigated. Results: Successful second-line eradication rates according to ITT analysis and PP analysis, respectively, were $79.9 \%$ and $92.4 \%$ for VPZ therapy and $83.6 \%$ and 93.3\% for PPI therapy. There were no significant differences between treatment groups. The eradication rates in those who had received first-line VPZ therapy previously according to ITT and PP analysis were $75.2 \%$ and $88.1 \%$, respectively; in contrast, values were $82.5 \%$ and $95.4 \%$, respectively, for those who had received first-line PPI therapy previously. In second-line therapy, the overall adverse event rate for VPZ therapy was the same as for PPI therapy. Conclusions: The efficacy and tolerability of metronidazole-containing second-line triple therapy with VPZ or a PPI were equivalent.
\end{abstract}




\section{Keywords}

Vonoprazan, Metronidazole, Proton Pump Inhibitor, Second-Line

Eradication, Helicobacter pylori

\section{Introduction}

Helicobacter pylori (H. pylori) in humans is commonly associated with gastroduodenal diseases, such as chronic gastritis, peptic ulcer diseases, mucosal-associated lymphoid tissue lymphoma (MALT lymphoma), and gastric neoplasms [1] [2]. Curative treatment of $H$. pylori infection was proved to markedly reduce the rate of recurrence of a variety of gastroduodenal diseases [2] [3]. In 2014, The International Agency for Research on Cancer (IARC) Working Group recommended H. pylori eradication as a strategy for preventing gastric cancer [4]. It encouraged all countries to explore the possibility of introducing population-based $H$. pylori screening and treatment programs adjusted to local healthcare environments and needs [5].

The standard triple therapy for H. pylori eradication is amoxicillin (AMPC), clarithromycin (CAM) and a proton pump inhibitor (PPI) twice a day for 1 week [6]. However, the $H$. pylori eradication rate for standard triple therapy is currently less than $80 \%$ in most parts of the world [7] [8]. The main cause of this ineffectiveness may be explained by bacterial resistance to CAM [7] [8]. Several approaches were proposed to overcome these low eradication rates; either sequential therapy or concomitant therapy achieved better results than standard triple therapy [9] [10]. The latest guidelines recommended quadruple therapies comprised of PPI + AMPC + CAM + metronidazole (MNZ) or PPI + bismuth + $\mathrm{MNZ}+$ tetracycline, with all treatments given for 14 days [2] [3].

Potassium-competitive acid blockers (P-CABs) are a new class of gastric acid suppressive agents. Similar to PPIs, P-CABs inhibit gastric hydrogen/potassiumATPase but, unlike PPIs, P-CABs inhibit the enzyme in a potassium-competitive and reversible manner [11]. Vonoprazan (VPZ) is a novel orally administered member of this class. VPZ has a potent and long-lasting anti-secretory effect on hydrogen/potassium-ATPase because of its high level of accumulation and slow clearance from gastric tissue [11] [12]. The acid-inhibitory effects of VPZ are much more potent than those of PPIs; therefore, it can be expected to be more effective when used for $H$. pylori eradication. A double-blind phase 3 study of triple therapy with VPZ (VAC) for first-line H. pylori eradication showed a high success rate of $92.6 \%$ [13]. Recently, a retrospective study with a large sample size [14], a meta-analysis [15] and prospective studies [16] [17] showed that the eradication rate of first-line VPZ (VAC) therapy was higher than that with PPI (PAC) therapy. In Japan, MNZ triple therapy is decided as second-line therapy under the National Health Insurance System. There were several reports on the results of MNZ triple therapy with VPZ (VAM) [13] [17]-[23]. The aim of this 
study was to evaluate the efficacy and tolerability of 7-day MNZ triple therapy with VPZ in comparison to PPI-based triple therapy for second-line therapy.

\section{Materials and Methods}

\subsection{Ethics}

This study was conducted in accordance with the Declaration of Helsinki. The institutional review board of Yamanashi Koseiren Health Care Center approved the study protocol (27-014).

\subsection{Study Participants}

This was a retrospective, single institution study. We reviewed the medical records of patients who underwent esophago-gastro-duodenoscopy screening as part of a general medical checkup program, who were infected with $H$. pylori, and who received $H$. pylori eradication therapy from January 2013 to July 2017 at Yamanashi Koseiren Health Care Center. All patients were $\geq 20$ years of age. In addition to age, exclusion criteria were: 1) consumption of antibiotics, non-steroidal anti-inflammatory drugs, antithrombotic agents, PPIs, or probiotics supplementation during the treatment; 2) allergy to antibiotics or PPIs; 3) previous gastric surgery; 4) severe concomitant cardiopulmonary disease or serious hepatic/renal dysfunction or malignancy; and 5) pregnancy or lactation. Patients who had previously received first-line CAM triple $H$. pylori eradication therapy were given second-line $H$. pylori eradication therapy. However, patients who had received treatment with both CAM and MTZ triple therapy for $H$. $p y$ lori eradication in the past were excluded.

Of the 790 consecutive patients who received second-line $H$. pylori eradication therapy, 7 who received the eradication therapies after stomach surgery, 38 who had received supplementation with probiotics, and 7 who were prescribed antibiotics or a PPI were excluded. As a result, 738 patients were enrolled in this study; the 274 patients who received VPZ therapy were compared to 464 patients who received PPI therapy (Figure 1).

\subsection{H. pylori Eradication}

The presence of $H$. pylori was confirmed before treatment by one or more of the following methods: the rapid urease test (PyloriTek; Serim Research Corp., Elkhart, IN, USA) or ${ }^{13} \mathrm{C}$-urea breath test (UBIT $100 \mathrm{mg}$ tablet/POCone; Otsuka Pharmaceutical Co., Tokyo, Japan) $\geq 2.5 \%$.

Patients who experienced first-line eradication failure were treated with rescue (second-line eradication) therapy. VPZ therapy (VAM) was comprised of $20 \mathrm{mg}$ of VPZ + $750 \mathrm{mg}$ of AMPC + $250 \mathrm{mg}$ of MNZ, all administered twice a day for 7 days; the entire dosage regimen was contained in one package (or VONOPION Pack; Takeda Pharmaceutical Co., Tokyo, Japan). The PPI therapy (PAM) was comprised of $30 \mathrm{mg}$ of LPZ (LAMPION Pack; Takeda Pharmaceutical Co., Tokyo, Japan) or $10 \mathrm{mg}$ of RPZ (Rabefine Pack; Eisai, Tokyo, Japan) + $750 \mathrm{mg}$ of 


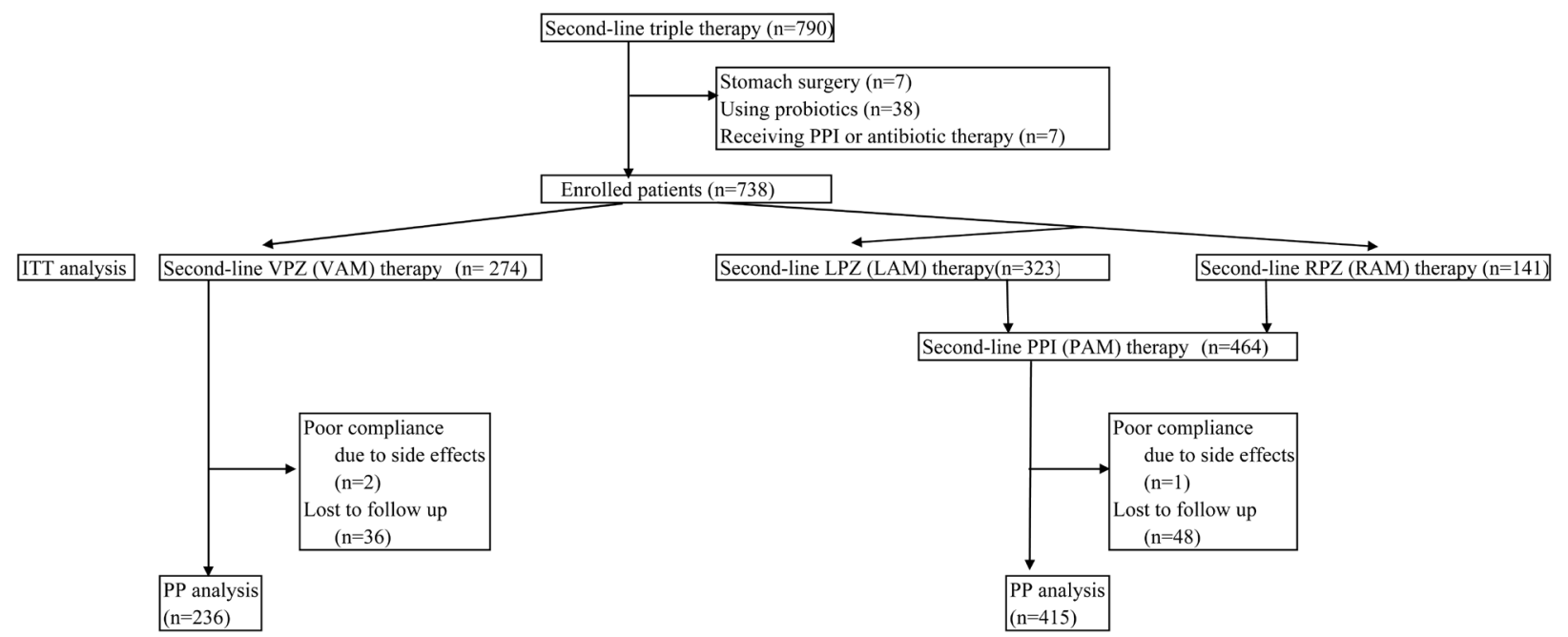

Figure 1. Study flow chart. ITT, intention-to-treat; PP, per-protocol; VPZ, vonoprazan; LPZ, lansoprazole; RPZ, rabeprazole; PPI, a proton pump inhibitor; AMPC, amoxicillin; MNZ, metronidazole; VAM, VPZ + AMPC + MNZ triple therapy; LAM, LPZ + $\mathrm{AMPC}+\mathrm{MNZ}$ triple therapy; RAM, RPZ + AMPC + MNZ triple therapy; PAM, a PPI + AMPC + MNZ triple therapy.

AMPC + $250 \mathrm{mg}$ of MNZ, all given twice a day for 7 days. The type of eradication therapy depended on the date of therapy; all patients treated before November 2013 received PPI therapy with LPZ (LAM) and those treated from November 2013 to February 2015 received eradication therapy using LPZ or rabeprazole (RPZ). Then from March 2015, all patients were treated with VAM.

Treatment duration and antibiotic dosages were determined according to the approved indication in Japan for H. pylori eradication. We instructed all patients not to smoke or drink alcohol during the eradication treatment.

Patients were requested to come to the Center again at least 8 weeks after the treatment period to evaluate their $H$. pylori status, to confirm compliance during therapy, and to identify possible side effects. H. pylori eradication was assessed by the ${ }^{13} \mathrm{C}$-urea breath test with success defined as a result of $<2.5 \%$.

\subsection{Endoscopic Findings}

All patients had undergone esophago-gastro-duodenoscopy before the first-line $H$. pylori eradication therapy. Diseases associated with $H$. pylori infection were diagnosed by endoscopic findings. The definition of atrophic gastritis was diagnosed as Closed type-2 (C-2) or higher by the classification of Kimura and Takemoto [24].

\subsection{Procedures}

The primary outcome in this study was second-line $H$. pylori eradication rates for VAM and PAM. We used intention-to-treat (ITT) and per-protocol (PP) analysis in the assessment of eradication efficacy. All enrolled patients who started medication were included in the ITT analysis regardless of compliance with medications. In the PP analysis, patients were excluded due to poor compliance or being lost to follow up. The secondary outcome in this study was the 
adverse-event rates related to the second-line eradication therapy.

\subsection{Statistical Analysis}

We compared continuous variables in the univariate analysis with the t test and presented arithmetic means and standard deviations. Categorical variables were analyzed with the chi-square test. For the primary and secondary outcomes, the frequency and two-sided 95\% confidence intervals (CIs) were calculated for each treatment group. $\mathrm{P}$ values less than 0.05 were considered statistically significant. All analyses were performed using JMP 12.1 software (SAS Institute, Cary, NC).

\section{Results}

\subsection{Baseline Characteristics of Patients Undergoing Second-Line Treatment}

Table 1 shows the baseline characteristics of patients who received second-line therapy. Patients in the VAM group were aged $58.2 \pm 11.6$ years $(50.7 \%$ males $)$ and those in the PAM group were aged $60.7 \pm 11.1$ years $(\mathrm{p}=0.0048)(48.9 \%$ males). The average BMI values were $22.7 \pm 3.4$ and $22.5 \pm 2.9$ for those receiving VPZ and PPI therapies, respectively, and there was no significant difference between these groups. Of those patients who received second-line VAM, all had previously received first-line VAC; therefore, $47.1 \%$ (129/274) of the patients receiving second-line VAM had been treated with first-line VAC $(\mathrm{p}<0.0001)$. Endoscopic findings showed significantly more atrophic changes in the PAM group than in the VAM group $(\mathrm{p}=0.0028)$. Successful second-line eradication rates according to ITT analysis and PP analysis, respectively, were $79.9 \%$ (95\% CI, $74.8 \%-84.2 \%$; $219 / 274)$ and $92.4 \%$ (95\% CI, $88.3 \%$ - 95.1\%; 218/236) for VAM and 83.6\% (95\% CI, 78.0\% - 86.7\%; 388/464) and 93.3\% (95\% CI, 90.4\% 95.3\%; 387/415) for PAM. There was no significant difference between treatment groups.

\subsection{Analysis of Subgroups Administered Second-Line VAM and PAM (Table 2)}

The second-line VAM group was divided into a VPZ usage (VAC) subgroup and a PPI usage (PAC) subgroup according to the first-line therapy administered. The eradication rates in the VAC subgroup according to ITT and PP analyses were $75.2 \%$ (95\%CI, $67.1 \%-81.8 \%$; 97/129) and $88.1 \%$ (95\%CI, 80.7\% - 92.9\%; 96/109), respectively; in contrast, values were $82.5 \%$ (95\% CI, $75.0 \%-88.2 \%$; 104/126) and 95.4\% (95\% CI, 89.8\% - 98.0\%; 104/109), respectively, for PAC subgroup. There were no significant differences in the eradication rates between the two first-line therapies.

The second-line PAM group was divided into the LPZ usage (LAM) subgroup and the RPZ usage (RAM) subgroup. There were no significant differences in the baseline characteristics of patients undergoing second-line LAM or secondline RAM. The eradication rates in the RAM subgroup according to ITT and PP 
Table 1. Characteristics of the patients who received the second-line eradication therapy for Helicobacter pylori.

\begin{tabular}{|c|c|c|c|}
\hline & VPZ (VAM) therapy & PPI (PAM) therapy & $p$ value \\
\hline No. of patients enrolled & 274 & 464 & \\
\hline Age (Years) & $58.2 \pm 11.6$ & $60.7 \pm 11.1$ & 0.0048 \\
\hline Gender & & & 0.6351 \\
\hline Male & 139 & 227 & \\
\hline Female & 135 & 237 & \\
\hline BMI $\left(\mathrm{kg} / \mathrm{m}^{2}\right)$ & $22.7 \pm 3.4$ & $22.5 \pm 2.9$ & 0.2901 \\
\hline First-line treatment & & & $<0.0001$ \\
\hline with VPZ (VAC) & 129 & 0 & \\
\hline with PPI (PAC) & 126 & 464 & \\
\hline unknown & 19 & & \\
\hline Endoscopic findings & & & 0.0028 \\
\hline No abnormality & 16 & 3 & \\
\hline Duodenal ulcer & 5 & 9 & \\
\hline Atrophic gastritis & 242 & 427 & \\
\hline Gastric ulcer & 10 & 25 & \\
\hline After ER for GC & 1 & 0 & \\
\hline Smoking (yes) & 38 & 65 & 0.9577 \\
\hline Drinking (yes) & 143 & 213 & 0.0988 \\
\hline Successful eradication & 219 & 388 & \\
\hline ITT analysis \% (95\% CI) & $79.9(74.8-84.2)$ & $83.6(78.0-86.7)$ & 0.2045 \\
\hline $\mathrm{PP}$ analysis \% (95\% CI) & $92.4(88.3-95.1)$ & $93.3(90.4-95.3)$ & 0.6736 \\
\hline Adverse events (\%, $95 \% \mathrm{CI})$ & $14(5.1 \%, 3.1-8.4)$ & $12(2.6 \%, 1.5-4.5)$ & 0.0724 \\
\hline
\end{tabular}

VPZ, vonoprazan; PPI, a proton pump inhibitor (lansoprazole or rabeprazole); AMPC, amoxicillin; CAM, clarithromycin; MNZ, metronidazole; VAM, VPZ + AMPC + MNZ triple therapy; PAM, a PPI + AMPC + MNZ triple therapy; BMI, body mass index; VAC, VPZ + AMPC + CAM triple therapy; PAC, a PPI + AMPC + CAM triple therapy; ER, endoscopic mucosal resection; GC, gastric cancer; ITT, intention-totreat; PP, per-protocol; CI, confidence interval.

analysis were $90.1 \%(95 \% \mathrm{CI}, 84.0 \%$ - 94.0\%; 127/141) and 94.1\% (95\%CI, 88.7\% $97.0 \%$; 127/135), respectively; in contrast, values were $80.8 \%$ (95\% CI, $76.2 \%$ $84.7 \% ; 261 / 323)$ and $92.9 \%$ (95\% CI, 89.2\% - 95.3\%; 260/280), respectively, for the LAM subgroup. There was a significant difference in eradication rates between the two second-line PPI therapies by ITT analysis $(\mathrm{p}=0.0131)$.

Of the 3 patients who had discontinued the treatment regimen, 1 VAM case and 1 LAM case experienced successful eradication of $H$. pylori.

\subsection{Adverse Events and Compliance}

In second-line therapy, the overall adverse event rate for VAM $(5.1 \%, 95 \% \mathrm{CI}, 3.1$ $8.4 ; 14 / 274)$ was the same as for PAM $(2.6 \%, 95 \% \mathrm{CI}, 1.5-4.5 ; 12 / 464)$ (Table 1$).$ 
Table 3 shows adverse events and their incidence in each group. The adverse event with the highest incidence was diarrhea in all groups $(0.9 \%-2.9 \%)$ and the second most common was skin rash in all groups $(0.6 \%-1.1 \%)$. All adverse events were less than grade 3 (Common Terminology Criteria for Adverse Event Version 4.0), and all events resolved spontaneously without treatment. H. pylori eradication therapy using VAM was interrupted in 1 patient who had a skin rash and 1 with abdominal pain.

\section{Discussion}

The second-line eradication rate of $H$. pylori with VAM was found to be $79.9 \%$ by ITT analysis and $92.4 \%$ by PP analysis, which was not significantly different

Table 2. Analysis of subgroups administered second-line VPZ (VAM) and PPI (PAM) therapies for Helicobacter pylori.

\begin{tabular}{|c|c|c|c|c|c|c|}
\hline \multirow[b]{2}{*}{ First-line treatment } & \multicolumn{3}{|c|}{ VPZ (VAM) therapy } & \multicolumn{3}{|c|}{ PPI (PAM) therapy } \\
\hline & VAC & PAC & $p$ value & & & \\
\hline Second-line treatment & & & & LAM & RAM & $p$ value \\
\hline No. of patients enrolled & 129 & 126 & & 323 & 141 & \\
\hline Age (Years) & $57.8 \pm 12.1$ & $58.7 \pm 11.1$ & 0.5205 & $60.8 \pm 11.2$ & $60.4 \pm 11.1$ & 0.8522 \\
\hline Gender & & & 0.9483 & & & 0.2053 \\
\hline Male & 64 & 62 & & 151 & 76 & \\
\hline Female & 65 & 64 & & 172 & 65 & \\
\hline $\operatorname{BMI}\left(\mathrm{kg} / \mathrm{m}^{2}\right)$ & $22.8 \pm 3.7$ & $22.5 \pm 3.0$ & 0.4157 & $22.6 \pm 2.9$ & $22.1 \pm 3.2$ & 0.1244 \\
\hline Endoscopic findings & & & 0.0835 & & & 0.1710 \\
\hline No abnormality & 13 & 2 & & 2 & 1 & \\
\hline Duodenal ulcer & 1 & 3 & & 5 & 4 & \\
\hline Atrophic gastritis & 110 & 116 & & 297 & 130 & \\
\hline Gastric ulcer & 4 & 5 & & 19 & 6 & \\
\hline After ER for GC & 1 & 0 & & 0 & 0 & \\
\hline Smoking (yes) & 15 & 19 & 0.4176 & 44 & 21 & 0.9101 \\
\hline Drinking (yes) & 68 & 68 & 0.8408 & 152 & 61 & 0.4152 \\
\hline Successful eradication & 97 & 104 & & 261 & 127 & \\
\hline $\begin{array}{c}\text { ITT analysis \% } \\
(95 \% \mathrm{CI})\end{array}$ & $\begin{array}{c}75.2 \\
(67.1-81.8)\end{array}$ & $\begin{array}{c}82.5 \\
(75.0-88.2)\end{array}$ & 0.1511 & $\begin{array}{c}80.8 \\
(76.2-84.7)\end{array}$ & $\begin{array}{c}90.1 \\
(84.0-94.0)\end{array}$ & 0.0131 \\
\hline $\begin{array}{c}\text { PP analysis \% } \\
(95 \% \mathrm{CI})\end{array}$ & $\begin{array}{c}88.1 \\
(80.7-92.9)\end{array}$ & $\begin{array}{c}95.4 \\
(89.8-98.0)\end{array}$ & 0.0826 & $\begin{array}{c}92.9 \\
(89.2-95.3)\end{array}$ & $\begin{array}{c}94.1 \\
(88.7-97.0)\end{array}$ & 0.6433 \\
\hline Adverse events & 5 & 7 & 0.5266 & 8 & 4 & 0.7489 \\
\hline
\end{tabular}

VPZ, vonoprazan; PPI, a proton pump inhibitor (lansoprazole or rabeprazole); AMPC, amoxicillin; CAM, clarithromycin; MNZ, metronidazole; VAM, VPZ + AMPC + MNZ triple therapy; PAM, a PPI + AMPC + MNZ triple therapy; VAC, VPZ + AMPC + CAM triple therapy; PAC, a PPI + AMPC + CAM triple therapy; LAM, Lansoprazole + AMPC + MNZ triple therapy; RAM, rabeprazole + amoxicillin + MNZ triple therapy; BMI, body mass index; ER, endoscopic mucosal resection; GC, gastric cancer; ITT, intention-totreat; PP, per-protocol; CI, confidence interval. 
Table 3. Adverse events in second-line MNZ triple therapy.

\begin{tabular}{cccc}
\hline & VPZ (VAM) therapy & LPZ (LAM) therapy & RPZ (RAM) therapy \\
\hline $\mathrm{n}$ & 274 & 323 & 141 \\
Diarrhea (\%) & $8(2.9)$ & $3(0.9)$ & $4(2.8)$ \\
Skin rash (\%) & $3(1.1)$ & $2(0.6)$ & 0 \\
Nausea, Vomiting (\%) & $1(0.4)$ & $1(0.3)$ & 0 \\
Abdominal pain (\%) & 1 & 0 & 0 \\
Constipation (\%) & 0 & $1(0.3)$ & 0 \\
Stomatitis (\%) & 0 & $1(0.3)$ & 0 \\
Abdominal fullness (\%) & $1(0.4)$ & $1(0.3)$ & $4(2.8)$ \\
Total (\%) & $14(5.1)$ & $8(2.5)$ & 0 \\
\hline
\end{tabular}

VPZ, vonoprazan; LPZ, lansoprazole; RPZ, rabeprazole; AMPC, amoxicillin; MNZ, metronidazole; VAM, $\mathrm{VPZ}+\mathrm{AMPC}+\mathrm{MNZ}$ triple therapy; LAM, LPZ + AMPC + MNZ triple therapy; RAM, RPZ + amoxicillin + MNZ triple therapy.

from findings for PAM. Adverse events did not differ between the VAM and PPI groups.

Through the Japanese National Health Insurance System, it was decided to use MNZ triple therapy as second-line therapy for $H$. pylori eradication. According to Japanese guidelines for clinical practice regarding $H$. pylori [25], firstline therapy is the standard triple therapy, which is PAC or VAC twice daily for 7 days, and second-line therapy is triple therapy, which is PAM or VAM twice daily for 7 days. Several studies have investigated the efficacy of second- line eradication of $H$. pylori with VAM, and successful eradication rates were $71.8 \%$ $98.0 \%$ by ITT analysis and $82.4 \%-98.0 \%$ by PP analysis [13] [17]-[23]. For second-line therapy, the effect of VAM was equivalent to that of PAM. Murakami et al. [13] showed high success rates for VAM in second-line $H$. pylori therapy, with an eradication rate of $98 \%$. The eradication rate in patients for whom the first-line VAC had failed is more important. Katayama et al. [23] reported that the eradication rate for $H$. pylori was $87.0 \%$ when VPZ was used as a second-line therapy (VAM) in patients for whom first-line VAC failed. In our cases, the successful first-line eradication rates according to ITT analysis and PP analysis, respectively, were $79.8 \%$ (95\% CI, 77.5\% - 81.9\%) and 91.4\% (95\% CI, 89.6\% - 92.9\%) for VAC and 66.3\% (95\% CI, 64.6\% - 68.0\%) and 78.9\% (95\% CI, $77.2 \%-80.5 \%)$ for PAC [14]. Among the patients who had not achieved eradication with first-line VAC the eradication rate was low with second-line VAM (75.2\% in the ITT analysis, $88.1 \%$ in the PP analysis); this rate tended to be lower than that among those who previously were given first-line PAC $(82.5 \%$ in the ITT analysis, $95.4 \%$ in the PP analysis). Inaba et al. [26] reported that secondline VAC was administered after first-line RAC failure and its success rate was $70.2 \%(26 / 37)$. When VAC therapy is provided as second-line therapy after firstline PPI therapy (PAC) failure, success in eradication may be achieved in a few patients. In the case of first-line VPZ (VAC) therapy, such success cannot be 
obtained with second-line VPZ (VAM) therapy.

The lack of superiority of second-line VPZ therapy shows that acid suppression is important for both AMPC and CAM in first-line therapy, but not for MNZ. That is, MTZ is very stable in gastric juice at $\mathrm{pH} 2$ to 7 , with a half-life of over 800 hours [27]. AMPC has poor stability, particularly at a low $\mathrm{pH}$, but nevertheless has a half-life of over 15 hours at $\mathrm{pH}$ 2. CAM is the most acid labile, having a half-life of less than 1 hour at $\mathrm{pH} 2$. AMPC and CAM are easily degraded in acidic conditions. In addition, $H$. pylori regains its replicative capability at $\mathrm{pH}>6$, so that it is more susceptible to antibiotics in this environment [27]. The sensitivity of $H$. pylori to MNZ is 4.2 times greater at $\mathrm{pH} 7.5$ than at pH 5.5 [28]. Likewise, the sensitivity of H. pylori to AMPC and CAM is 8.3 to 20 and 160 times greater, respectively, at $\mathrm{pH} 7.5$ than at $\mathrm{pH}$ 5.5.

According to the Toronto consensus [3], a meta-analysis of data from randomized controlled trials (RCTs) assessing bismuth quadruple therapy after failure of standard triple therapy reported an eradication success rate of $78 \%$ (95\% CI, $75 \%-81 \%)$. There was a trend toward higher eradication rates with longer durations of therapy. The Maastricht V/Florence consensus report recommended either a bismuth-containing quadruple therapy or a levofloxacin-containing triple therapy after failure of standard triple therapy [2]. Similar efficacy of PPI-levofloxacin-amoxicillin triple therapy and bismuth-containing quadruple therapy after first-line treatment failure with PPI-amoxicillin-clarithromycin was shown, providing cure rates of $76 \%$ and $78 \%$, respectively. We consider that the eradication rates of the second-line therapies recommended by well-known guidelines and that of second-line MNZ triple therapy in Japan were similar, although there have been no comparative studies.

The prevalence of MNZ resistance to the treatment of $H$. pylori is $9 \%-12 \%$ in Japan [29]. However, this resistance rate has been increasing in Japan recently $(30 \%-37.8 \%)$ [30]. According to antimicrobial susceptibility testing in Japan, the $\mathrm{MNZ}$ resistance rate after eradication therapy increased from $3 \%$ without an eradication history to $13.3 \%$ after first-line therapy failure and $52.4 \%$ for secondline therapy failure [30]. In the future, MNZ resistance rates will increase in Japan as in many countries [31].

A limitation of this study was its non-randomized and retrospective study design. In addition, this was a single-institution study and included only Japanese patients. We did not consider CAM and MNZ resistance, which have been reported to be major factors related to the success of $H$. pylori eradication therapy. In conclusion, efficacy and tolerability of 7-day VAM were equivalent to those for PAM for second-line therapy.

\section{Supporting Foundations}

None.

\section{Disclosure}

EN received scholarship funds for the research from Otsuka Pharmaceutical Co., 
Ltd. and Eiasi Co., Ltd. The other authors have no conflicts of interest to disclose.

\section{References}

[1] Suerbaum, S. and Michetti, P. (2002) Helicobacter Pylori Infection. The New England Journal of Medicine, 347, 1175-1186. https://doi.org/10.1056/NEJMra020542

[2] Malfertheiner, P., Megraud, F., O’Morain, C.A., Gisbert, J.P., Kuipers, E.J., Axon, A.T., Bazzoli, F., Gasbarrini, A., Atherton, J., Graham, D.Y., Hunt, R., Moayyedi, P., Rokkas, T., Rugge, M., Selgrad, M., Suerbaum, S., Sugano, K. and El-Omar, E.M., on behalf of the European Helicobacter and Microbiota Study Group and Consensus Panel (2017) Management of Helicobacter Pylori Infection-The Maastricht V/Florence Consensus Report. Gut, 66, 6-30. https://doi.org/10.1136/gutjnl-2016-312288

[3] Fallone, C.A., Chiba, N., van Zanten, S.V., Fischbach, L., Gisbert, J.P., Hunt, R.H., Jones, N.L., Render, C., Leontiadis, G.I., Moayyedi, P. and Marshall, J.K. (2016) The Toronto Consensus for the Treatment of Helicobacter pylori Infection in Adults. Gastroenterology, 151, 51-69. https://doi.org/10.1053/j.gastro.2016.04.006

[4] International Agency for Research on Cancer (2014) H. pylori Eradication as a Strategy for Preventing Gastric Cancer.

http://www.iarc.fr/en/publications/pdfs-online/wrk/wrk8/Helicobacter_pylori_Erad ication.pdf

[5] Tsuda, M., Asaka, M., Kato, M., Matsushima, R., Fujimori, K., Akino, K., Kikuchi, S., Lin, Y. and Sakamoto, N. (2017) Effect on Helicobacter pylori Eradication Therapy against Gastric Cancer in Japan. Helicobacter, 22, e12415. https://doi.org/10.1111/hel.12415

[6] Wang, B., Lv, Z.F., Wang, Y.H., Wang, H., Liu, X.Q., Xie, Y. and Zhou, X.J. (2014) Standard Triple Therapy for Helicobacter pylori Infection in China: A Meta-Analysis. World Journal of Gastroenterology, 20, 14973-14985. https://doi.org/10.3748/wjg.v20.i40.14973

[7] Graham, D.Y. and Fischbach, L. (2010) Helicobacter pylori Treatment in the Era of Increasing Antibiotic Resistance. Gut, 59, 1143-1153.

https://doi.org/10.1136/gut.2009.192757

[8] Zhang, M. (2015) High Antibiotic Resistance Rate: A Difficult Issue for Helicobacter pylori Eradication Treatment. World Journal of Gastroenterology, 21, 13432-13437. https://doi.org/10.3748/wjg.v21.i48.13432

[9] Jung, S.M., Cheung, D.Y., Kim, J.I., Kim, I. and Seong, H. (2016) Comparing the Efficacy of Concomitant Therapy with Sequential Therapy as the First-Line Therapy of Helicobacter pylori Eradication. Gastroenterology Research and Practice, 2016, Article ID: 1293649. https://doi.org/10.1155/2016/1293649

[10] Tepeš, B., Vujasinović, M., Šeruga, M., Stefanovič, M., Forte, A. and Jeverica, S. (2016) Randomized Clinical Trial Comparing 10-Day Sequential, 7-Day Concomitant and 7-Day Standard Triple Therapies for Helicobacter pylori Eradication. European Journal of Gastroenterology \& Hepatology, 28, 676-683. https://doi.org/10.1097/MEG.0000000000000590

[11] Hori, Y., Imanishi, A., Matsukawa, J., Tsukimi, Y., Nishida, H., Arikawa, Y., Hirase, K., Kajino, M. and Inatomi, N. (2010) 1-[5-(2-Fluorophenyl)-1-(pyridin-3-ylsulfonyl)-1 $H$-pyrrol-3-yl]- $N$-methylmethanamine Monofumarate (TAK-438), a Novel and Potent Potassium-Competitive Acid Blocker for the Treatment of Acid-Related Diseases. Journal of Pharmacology and Experimental Therapeutics, 335, 231-238. https://doi.org/10.1124/jpet.110.170274 
[12] Sakurai, Y., Nishimura, A., Kennedy, G., Hibberd, M., Jenkins, R., Okamoto, H., Yoneyama, T., Jenkins, H., Ashida, K., Irie, S. and Täubel, J. (2015) Safety, Tolerability, Pharmacokinetics, and Pharmacodynamics of Single Rising TAK-438 (Vonoprazan) Doses in Healthy Male Japanese/Non-Japanese Subjects. Clinical and Translational Gastroenterology, 6, e94. https://doi.org/10.1038/ctg.2015.18

[13] Murakami, K., Sakurai, Y., Shiino, M., Funao, N., Nishimura, A. and Asaka, M. (2016) Vonoprazan, a Novel Potassium-Competitive Acid Blocker, as a Component of First-Line and Second-Line Triple Therapy for Helicobacter pylori Eradication: A Phase III, Randomised, Double-Blind Study. Gut, 65, 1439-1446.

https://doi.org/10.1136/gutjnl-2015-311304

[14] Miura, M., Ohtaka, M., Hanawa, M., Shimura, N., Yoda, Y. and Suzuki, S. (2017) Gastric Mucosal Atrophy Might Be Associated with the Efficacy of First-Line Therapy Using Vonoprazan for Helicobacter pylori. Open Journal of Gastroenterology, 7, 243-259. https://doi.org/10.4236/ojgas.2017.79026

[15] Jung, Y.S., Kim, E.H. and Park, C.H. (2017) Systematic Review with Meta-Analysis: The Efficacy of Vonoprazan-Based Triple Therapy on Helicobacter pylori Eradication. Alimentary Pharmacology \& Therapeutics, 46, 106-114. https://doi.org/10.1111/apt.14130

[16] Maruyama, M., Tanaka, N., Kubota, D., Miyajima, M., Kimura, T., Tokutake, K., Imai, R., Fujisawa, T., Mori, H., Matsuda, Y., Wada, S., Horiuchi, A. and Kiyosawa, K. (2017) Vonoprazan-Based Regimen Is More Useful than PPI-Based One as a First-Line Helicobacter pylori Eradication: A Randomized Controlled Trial. Canadian Journal of Gastroenterology and Hepatology, 2017, Article ID 4385161. https://doi.org/10.1155/2017/4385161

[17] Sue, S., Kuwashima, H., Iwata, Y., Oka, H., Arima, I., Fukuchi, T., Sanga, K., Inokuchi, Y., Ishii, Y., Kanno, M., Terada, M., Amano, H., Naito, M., Iwase, S., Okazaki, H., Komatsu, K., Kokawa, A., Kawana, I., Morimoto, M., Saito, T., Kunishi, Y., Ikeda, A., Takahashi, D., Miwa, H., Sasaki, T., Tamura, T., Kondo, M., Shibata, W. and Maeda, S. (2017) The Superiority of Vonoprazan-Based First-Line Triple Therapy with Clarithromycin: A Prospective Multi-Center Cohort Study on Helicobacter pylori Eradication. Internal Medicine, 56, 1277-1285.

https://doi.org/10.2169/internalmedicine.56.7833

[18] Matsumoto, H., Shiotani, A., Katsumata, R., Fujita, M., Nakato, R., Murao, T., Ishii, M., Kamada, T., Haruma, K. and Graham, D.Y. (2016) Helicobacter pylori Eradication with Proton Pump Inhibitors or Potassium-Competitive Acid Blockers: The Effect of Clarithromycin Resistance. Digestive Diseases and Sciences, 61, 3215-3220. https://doi.org/10.1007/s10620-016-4305-0

[19] Yamada, S., Kawakami, T., Nakatsugawa, Y., Suzuki, T., Fujii, H., Tomatsuri, N., Nakamura, H., Sato, H., Okuyama, Y., Kimura, H. and Yoshida, N. (2016) Usefulness of Vonoprazan, a Potassium Ion-Competitive Acid Blocker, for Primary Eradication of Helicobacter pylori. World Journal of Gastrointestinal Pharmacology and Therapeutics, 7, 550-555. https://doi.org/10.4292/wjgpt.v7.i4.550

[20] Sakurai, K., Suda, H., Ido, Y., Takeichi, T., Okuda, A., Hasuda, K. and Hattori, M. (2017) Comparative Study: Vonoprazan and Proton Pump Inhibitors in Helicobacter pylori Eradication Therapy. World Journal of Gastroenterology, 23, 668-675. https://doi.org/10.3748/wjg.v23.i4.668

[21] Tsujimae, M., Yamashita, H., Hashimura, H., Kano, C., Shimoyama, K., Kanamori, A., Matsumoto, K., Koizumi, A., Momose, K., Eguchi, T., Fukuchi, T., Fujita, M. and Okada, A. (2016) A Comparative Study of a New Class of Gastric Acid Suppressant Agent Named Vonoparazan versus Esomeprazole for the Eradication of 
Helicobacter pylori. Digestion, 94, 240-246. https://doi.org/10.1159/000454762

[22] Nishizawa, T., Suzuki, H., Fujimoto, A., Kinoshita, H., Yoshida, S., Isomura, Y., Toyoshima, A., Kanai, T., Yahagi, N. and Toyoshima, O. (2017) Effects of Patient Age and Choice of Antisecretory Agent on Success of Eradication Therapy for $\mathrm{He}$ licobacter pylori Infection. Journal of Clinical Biochemistry and Nutrition, 60, 208-210.

[23] Katayama, Y., Toyoda, K., Kusano, Y., Suda, T., Adachi, S., Terauchi, I., Oka, S., Takahashi, M. and Tamano, M. (2017) Efficacy of Vonoprazan-Based Second-Line Helicobacter pylori Eradication Therapy in Patients for Whom Vonoprazan-Based First-Line Treatment Failed. Gut, 66, 752-753. https://doi.org/10.1136/gutjnl-2016-312028

[24] Kimura, K. and Takemoto, T. (1969) An Endoscopic Recognition of the Atrophic Border and Its Significance in Chronic Gastritis. Endoscopy, 1, 87-97.

https://doi.org/10.1055/s-0028-1098086

[25] Kato, M. (2016) III 治療, 編集日本へリコバクタ一学会ガイドライン作成委員 会先端医学社, H. pylori 感染診断の診断と治療のガイドライン (2016 改定版), [III Treatment. In: The Japanese Society for Helicobacter Research, Ed., Japanese Guideline for Management of Helicobacter pylori Infection,] SENTAN IGAKU-SHA, Ltd., Tokyo, 46-58. (in Japanese)

[26] Inaba, T., Iwamuro, M., Toyokawa, T. and Okada, H. (2016) Letter: Promising Results of Helicobacter pylori Eradication with Vonoprazan-Based Triple Therapy After Failure of Proton Pump Inhibitor-Based Triple Therapy. Alimentary Pharmacology \& Therapeutics, 43, 179-180. https://doi.org/10.1111/apt.13462

[27] Sachs, G., Scott, D.R. and Wen, Y. (2011) Gastric Infection by Helicobacter pylori. Current Gastroenterology Reports, 13, 540-546. https://doi.org/10.1007/s11894-011-0226-4

[28] Labenz, J. (2001) Current Role of Acid Suppressants in Helicobacter pylori Eradication Therapy. Best Practice \& Research Clinical Gastroenterology, 15, 413-431. https://doi.org/10.1053/bega.2001.0188

[29] Kato, M., Yamaoka, Y., Kim, J.J., Reddy, R., Asaka, M., Kashima, K., Osato, M.S., El-Zaatari, F.A., Graham, D.Y. and Kwon, D.H. (2000) Regional Differences in Metronidazole Resistance and Increasing Clarithromycin Resistance among Helicobacter pylori Isolates from Japan. Antimicrobial Agents and Chemotherapy, 44, 2214-2216. https://doi.org/10.1128/AAC.44.8.2214-2216.2000

[30] Hashinaga, M., Okimoto, T., Kodama, M., Mizukami, K., Ogawa, R., Okamoto, K., Shuto, M., Fukuda, K., Sonoda, H., Fukuda, M., Honda, S., Yamaoka, Y. and Murakami, K. (2016) わが国における薬剂耐性 Helicobacter pylori の現状-2013-2014 年度耐性菌サーベイランスの集計報告. [Current Status of Drug Resistance Helicobacter pylori in Japan-Total Report of Resistant Bacterial Surveillance for 2013 to 2014.] Japanese Journal of Helicobacter Research, 17, 45-49. (In Japanese)

[31] Thung, I., Aramin, H., Vavinskaya, V., Gupta, S., Park, J.Y., Crowe, S.E. and Valasek, M.A. (2016) Review Article: The Global Emergence of Helicobacter pylori Antibiotic Resistance. Alimentary Pharmacology \& Therapeutics, 43, 514-533. https://doi.org/10.1111/apt.13497 